This document was prepared in conjunction with work accomplished under Contract No. DE-AC09-96SR18500 with the U.S. Department of Energy.

This work was prepared under an agreement with and funded by the U.S. Government. Neither the U. S. Government or its employees, nor any of its contractors, subcontractors or their employees, makes any express or implied: 1 . warranty or assumes any legal liability for the accuracy, completeness, or for the use or results of such use of any information, product, or process disclosed; or 2 . representation that such use or results of such use would not infringe privately owned rights; or 3 . endorsement or recommendation of any specifically identified commercial product, process, or service. Any views and opinions of authors expressed in this work do not necessarily state or reflect those of the United States Government, or its contractors, or subcontractors. 


\title{
Improving Thermal Performance of Radioactive Material Drum Type Packages by Using Heat Pipes
}

\author{
Narendra K. Gupta \\ Savannah River National Laboratory, Aiken, SC 29808 \\ nick.gupta@srnl.doe.gov
}

\begin{abstract}
This paper presents a feasibility study to improve thermal loading of existing radioactive material packages by using heat pipes. The concept could be used to channel heat in certain directions and dissipate to the environment. The concept is applied to a drum type package because the drum type packages are stored and transported in an upright position. This orientation is suitable for heat pipe operation that could facilitate the heat pipe implementation in the existing well proven package designs or in new designs where thermal loading is high. In this position, heat pipes utilize gravity very effectively to enhance heat flow in the upward direction Heat pipes have extremely high effective thermal conductivity that is several magnitudes higher than the most heat conducting metals. In addition, heat pipes are highly unidirectional so that the effective conductivity for heat transfer in the reverse direction is greatly reduced. The concept is applied to the 9977 package that is currently going through the DOE certification review. The paper presents computer simulations using typical of-the-shelf heat pipe available configurations and performance data for the 9977 package. A path forward is outlined for implementing the concepts for further study and prototype testing.
\end{abstract}

\section{INTRODUCTION}

\section{Heat Pipe Principle}

A heat pipe is a simple device that can quickly transfer heat from one point to another. They are often referred to as the "superconductors" of heat as they possess an extra ordinary heat transfer capacity \& rate with almost no heat loss. It acts like a high conductance thermal conductor. Due to its thermal-physical properties, its heat transfer rate is thousand's times greater than that of the best solid heat conductor of the same dimensions. They are totally passive heat transfer systems, having no moving parts to wear out and requiring no energy to operate. Heat pipes offer the design engineer low-cost packaging flexibility because they can be manufactured in a variety of shapes and sizes. Their light weight and compact size also make them the ideal choice for spaceconstrained applications. The basic heat pipe is a closed container consisting of a capillary wick structure and a small amount of vaporizable fluid. The heat pipe employs an evaporatingcondensing cycle, which accepts heat from an external source, uses this heat to evaporate the liquid (latent heat) and then releases latent heat by reverse transformation (condensation) at a heat sink region. This process is repeated continuously by a return feed mechanism of the condensed fluid back to the heat zone. Figure 1 depicts the heat pipe principle [1].

\section{Heat Pipe Design Guidelines}

1) Operational parameters:

a. Heat load and geometry of the heat source.

b. Possible heat sink location, the distance and orientation relative to the heat source.

c. Temperature profile of heat source, heat sink and ambient d. Environmental condition (such as existence of corrosive gas)

2) Select the pipe material, wick structure, and working fluid.

a. Determine the working fluid appropriate for your application

b. Select pipe material compatible to the working fluid

c. Select wick structure for the operating orientation

d. Decide on the protective coating.

3) Determine the length, size, and shape of the heat pipe

Table 1 gives the typical operating characteristics of heat pipes for moderate temperatures [2].

\begin{tabular}{|c|c|c|c|c|}
\hline $\begin{array}{l}\text { Temperature } \\
\text { Range }\left({ }^{\circ} \mathrm{C}\right)\end{array}$ & Working Fluid & $\begin{array}{l}\text { Vessel } \\
\text { Material }\end{array}$ & $\begin{array}{l}\text { Measured } \\
\text { axial }{ }^{3} \text { heat flux } \\
\left(\mathrm{kW} / \mathrm{cm}^{2}\right)\end{array}$ & $\begin{array}{l}\text { Measured } \\
\text { surface } \\
\text { flux }\left(W / \mathrm{cm}^{2}\right)\end{array}$ \\
\hline-200 to -80 & Liquid Nitrogen & $\begin{array}{l}\text { Stainless } \\
\text { Steel }\end{array}$ & $0.067 @-163^{\circ} \mathrm{C}$ & $1.01 @-163^{\circ} \mathrm{C}$ \\
\hline-70 to +60 & Liquid Ammonia & $\begin{array}{c}\text { Nickel, } \\
\text { Aluminum, } \\
\text { Stainless } \\
\text { Steel }\end{array}$ & 0.295 & 2.95 \\
\hline-45 to +120 & Methanol & $\begin{array}{l}\text { Copper, } \\
\text { Nickel, } \\
\text { Stainless } \\
\text { Steel }\end{array}$ & $0.45 @ 100^{\circ} \mathrm{C}^{\mathrm{x}}$ & $75.5 @ 100^{\circ} \mathrm{C}$ \\
\hline+5 to +230 & Water & $\begin{array}{l}\text { Copper, } \\
\text { Nickel }\end{array}$ & $0.67 @ 200^{\circ} \mathrm{C}$ & $146 @ 170^{\circ} \mathrm{C}$ \\
\hline+190 to +550 & $\begin{array}{l}\text { Mercury } \\
+0.02 \% \\
\text { Magnesium } \\
+0.001 \%\end{array}$ & $\begin{array}{l}\text { Stainless } \\
\text { Steel }\end{array}$ & $25.1 @ 360^{\circ} \mathrm{C}^{*}$ & $181 @ 750^{\circ} \mathrm{C}$ \\
\hline
\end{tabular}


${ }^{8}$ Varies with temperature

$\mathrm{X}_{\text {Using threaded artery wick }}$

*Tested at Los Alamos National Laboratory

Fig 2 gives the performance of heat pipes with diameter from 3 to $22.23 \mathrm{~mm}$ [3]. For the best performance, the application should have gravity working with the system; that is, the evaporator section (heated) should be lower, with respect to gravity, than the condenser (cooling) section. In other orientations where gravity is not aiding the condensed liquid return, the overall performance will be degraded. Performance degradation depends on a number of factors including wick structure, length and working fluid of the heat pipe along with heat flux of the application. Careful design can minimize the performance loss and allow an accurate prediction performance.

Fig. 3 shows the heat pipe performance for the four typical wick structures used in the industry [3]. Fig. 3 is for the vertical orientation where the gravity assist is available for the liquid to flow down to the evaporator section of the heat pipe. The figure shows that the thermal resistance is lowest for the groove type of wick structure. It is noteworthy that a $3 \mathrm{~mm}$ diameter heat pipe can be used to dissipate 10 watts. Since the power to be dissipated in 9977 package is 19 watts, it appears that a heat pipe $3 \mathrm{~mm}$ or smaller should be more than adequate for improving the 9977 thermal performance.

The rate of vapor traveling from the evaporator to the condenser is governed by the difference in vapor pressure between them. It is also affected by the diameter and the length of the heat pipe. In the large diameter heat pipe, the cross sectional area will allow higher vapor volume to be transported from the evaporator to the condenser than in a small diameter pipe. Fig 4 compares the heat transport of heat pipes with different diameters. We can see in Fig 4 that the heat pipes transport more heat at higher operational temperatures. The rate of working fluid return from the condenser to the evaporator is governed by capillary limit and is the reciprocal function of the heat pipe length. A longer heat pipe transports less heat versus the same heat pipe with a shorter length. In Fig 4, the unit of the Y-axis is QmaxLeff $(\mathrm{W}-\mathrm{m})$ representing the amount of heat a pipe can carry per meter length. If the pipe is half a meter, it can carry twice the wattage.

The 9977 package is expected to operate well over $100^{\circ} \mathrm{C}$, and therefore several $3 \mathrm{~mm}$ diameter heat pipes evenly spaced around the containment vessel will be sufficient to channel the heat to the top of the package. Considering these factors, a drum type package like 9977 is a good candidate. Now we will examine the 9977 package design against these available performance attributes.

\section{PACKAGE}

The 9977 package is designed to transport fissile materials across the Department of Energy (DOE) complex. The package consists of various subsystems to guard against leakage of toxic nuclear material, radiation leakage, and nuclear criticality during storage, Normal Conditions of Transport (NCT) and under Hypothetical Accident Conditions (HAC) during transport. These safety features are accomplished by providing a single leak tight containment vessel to prevent payload leakage and several layers of different insulating materials in a postulated fire during HAC. The maximum allowed content decay-heat rate is 19 watts. Figure 5 shows the schematic of the 9977 package.

The 9977 package is designed to meet the requirements of Code of Federal Regulations 10 CFR 71 [4] to ensure that the environment and public health are not adversely impacted during NCT and HAC. The requirements set limits for the fissile material quantity and set criteria for the structural, thermal, shielding, criticality, fabrication, and quality assurance requirements. Thermal performance is tied to the temperature design limits of the system components.

\section{Geometry}

The 9977 package is designed to reject heat passively. Thermal protection for the 9977 is provided by an insulation filled drum and its bolt-on lid, each having multiple layers of insulating materials. Figure 5 is a schematic of the principal thermal features of the 9977. The drum consists of a 35-gallon shell with an inner liner weldment. The liner weldment is wrapped with Fiberfrax ${ }^{\mathbb{B}}$ and the remaining drum volume is filled with polyurethane foam. The lid weldment consists of upper and lower shells filled with Fiberfrax, Min-K 2000, and TR-19 Block insulating materials. The important dimension for the implementation of heat pipe is the distance between the center of the heat generating payload, located at the bottom of the $\mathrm{CV}$, and the top of the package. The heat is to be rejected at the top the package. This dimension is about 20 inches. This determines the length of the heat pipe.

\section{Operating Parameters}

The maximum content temperature is about $350^{\circ} \mathrm{F}$ at 19 watts in the current design. The ambient temperature is $100^{\circ} \mathrm{F}$. The package is subjected to solar heat flux that is mandated in the federal regulations given in $10 \mathrm{CFR} 71$. It is desired to increase the payload wattage to 50 watts and still meet the component temperature design limits. It is desired to keep the $\mathrm{CV}$ wall temperature to less than $149^{\circ} \mathrm{C}\left(300^{\circ} \mathrm{F}\right)$ and the foam temperatures to less than $121^{\circ} \mathrm{C}\left(250^{\circ} \mathrm{F}\right)$.

\section{Material Selection}

Table 1 gives the idea about the type of heat pipe to be selected for this application. A copper nickel heat type with water as the fluid will meet the requirements. Water is a concern for criticality but the $\mathrm{CV}$ is tested to meet the leak-tight requirements and therefore this is not a concern. The fins must be made of high thermal conductivity material like aluminum or copper. Fins will melt during fire and prevent heat transmission back towards the $\mathrm{CV}$ during $\mathrm{HAC}$ fire. However, fin performance cannot be relied upon during the post fire transient. The package lid is constructed from type 304 stainless steel and will house the condenser to which the fin structure will be welded. The lid structure must be strong enough to withstand 30 feet HAC drops.

\section{Heat Pipe Geometry}

Based on the wattage, a $3 \mathrm{~mm}$ heat pipe should suffice. The heat pipes can be arranged circumferentially around the $\mathrm{CV}$ in a structure to provide rigidity during loading and unloading operations of the package. The lid must be removed in these operations. Additional handling precautions will be required to ensure the heat pipe assembly structure is not damaged. A fin structure (integral to the heat pipe) is necessary to dissipate heat at the top of the package. This fin structure must be an integral part of the package lid to promote easy handling during assembly and disassembly of the package. The heat pipe is imagined to be a two walled shell with a 3 $\mathrm{mm}$ hollow annular space. A 3D rendering is shown in Figure 6. 


\section{MATHEMATICAL MODEL}

Heat pipes are structures that transport heat by the evaporation and condensation of a working fluid. The governing mass and heat transfer equations applicable to model such a complex component should be able to analyze mixture of two phase flow and noncondensible gases. The various equations address conservation of mass, momentum and energy. In addition thermodynamic state equation and boundary conditions must be properly stated. No attempt is made to list these equations here. The reader is advised to many reference books on the subject and to Reference 5 for the governing equations applicable to a heat pipe system. A computer code called THROHPUT [6] developed at Los Alamos National $\mathrm{Lab}$ is also available to analyze more practical systems.

\section{Thermal Model}

A general heat transfer code Patran/Thermal [7] was used to model the heat pipe performance in 9977 package. This code was used to design the current package and the heat pipe simulation results will be compared against the results in the existing 9977 documentation [8]. Also, only thermal performance during NCT will be assessed in this paper. Thermal performance during NCT bounds the temperatures during HAC.

The Patran/Thermal computer code cannot model fluid flow and therefore the approach adopted here is to calculate the effective axial thermal conductivity of a practical heat pipe size suitable for this application. For this purpose the performance curves shown in Figures 2, 3, 4 [2] were used. A heat pipe of length 20 inches (500 $\mathrm{mm}$ ) and $3 \mathrm{~mm}$ diameter was chosen for this application. The effective thermal conductivity can be calculated by the formula,

$\mathrm{Q}=\mathrm{kA} \Delta \mathrm{T} / \mathrm{d}$

Where :

$\mathrm{k}$ is the effective axial thermal conductivity $\mathrm{A}$ is the crossectional area of the heat pipe $\Delta \mathrm{T}$ is the temperature difference along the pipe length $\mathrm{d}$ is the length of the pipe

$\mathrm{Q} / \mathrm{A}$ is the axial heat flux and is available from Table 1. For the heat pipe using water, this is $0.67 \mathrm{kw} / \mathrm{cm}^{2}$ at $200^{\circ} \mathrm{C} . \Delta \mathrm{T}$ can be obtained from Figure 3. Figure 3 is applicable for pipe lengths of $200 \mathrm{~mm}$ only. The temperature drop for the $500 \mathrm{~mm}$ long pipe is obtained by extrapolation. It is realized that extrapolation might not be applicable and it may underpredict the temperature drop necessary to deliver the necessary wattage. However, this can be compensated by providing additional heat pipes around the $\mathrm{CV}$. The extrapolation gives a temperature drop of about $2.9^{\circ} \mathrm{C}$ along the length of the $500 \mathrm{~mm}$ long pipe.

Figure 4 gives an idea how much power can be delivered by a $3 \mathrm{~mm}$ heat pipe per meter length. If the heat pipe is operating at $60^{\circ} \mathrm{C}$ (it is expected to operate at $100^{\circ} \mathrm{C}$ ), a $3 \mathrm{~mm}$ pipe can deliver about $1 \mathrm{watt} /$ meter. For a $1 / 2$ meter long pipe, it is expected that a 3 $\mathrm{mm}$ pipe can deliver 2 watts. If this is the case, then 10 pipes can be arranged around the CV to deliver 20 watts to the sink. There is enough space around 6 inch $\mathrm{CV}$ to accommodate 10 pipes. In fact the annular space around the $\mathrm{CV}$ is about $600 \mathrm{~mm}$ long and it can accommodate as many as 200 pipes having an OD of $3 \mathrm{~mm}$. This indicates that heat pipes arranged continuously around the $\mathrm{CV}$ will be capable of much more power than just 20 watts. In fact this will be evident from computer simulation.

To deliver 2 watts per pipe, a $\Delta \mathrm{T}$ of about $5.8^{\circ} \mathrm{C} \approx 6^{\circ} \mathrm{C}$ is required. Eq. 1 now gives a $\mathrm{k}=5600 \mathrm{w} / \mathrm{cm}^{\circ}{ }^{\circ} \mathrm{C}$. Since the pipe will be operating at $100^{\circ} \mathrm{C}$ only and not at $200^{\circ} \mathrm{C}$ (see Table 1), a value of $\mathrm{k}=2800 \mathrm{w} / \mathrm{cm}-{ }^{\circ} \mathrm{C}\left(161784 \mathrm{Btu} / \mathrm{ft}-\mathrm{hr}-{ }^{\circ} \mathrm{F}\right)$ will be used in the computer simulation. This approximation would also compensate for the extrapolation used for the $500 \mathrm{~mm}$ long pipe in Figure 3. This reduction is conservative and if the simulation shows that this heat pipe with an effective $\mathrm{k}$ of $2800 \mathrm{w} / \mathrm{cm}-{ }^{\circ} \mathrm{C}$ cannot transfer 20 watts along a $500 \mathrm{~mm}$ length, the design will be suspect.

The next big challenge in the design of the heat pipe for this application is to design the heat sink that is capable of dissipating 20 to 50 watts to the $38^{\circ} \mathrm{C}$ ambient by natural convection. A review of the heat sink designs on the web shows that a fin type of heat sink that will fit the available surface on the drum lid is made by ThermaFlo [9]. This is an aluminum fin heat sink E3113. This design can be bonded to the existing surface. Figure 7 shows the dimensions of E3113. Its operating characteristics are shown in Figures 8 and 9. For this heat sink to dissipate 50 watts of power, a temperature rise of $40^{\circ} \mathrm{C}$ will be required at the sink base. If the heat pipe is going to operate at $100^{\circ} \mathrm{C}$, Figure 8 shows that this heat sink can dissipate up to 80 watts of power. Figure 10 shows the color representation (materials) of the thermal model with the fins. The heat pipe is shown in blue.

\section{Computer Simulations}

From Figure 9, the heat sink E3113 has a thermal resistance of about $0.75{ }^{\circ} \mathrm{C} / \mathrm{W}$ in the power range of 50 to 80 watts. Since the heat transfer area $\left(154 \mathrm{in}^{2}\right)$ at the top of package lid is known, an effective heat transfer coefficient $h$ can be calculated. This comes out to be $13.3 \mathrm{~W} / \mathrm{m}^{2}-{ }^{\circ} \mathrm{C}$. The vertical part of the heat pipe was modeled as a pseudo pipe with an axial conductivity of $2800 \mathrm{w} / \mathrm{cm}-{ }^{\circ} \mathrm{C}$. The base of the heat sink was modeled as an isotropic metal with this conductivity. The fins were allowed to radiate heat to the $38^{\circ} \mathrm{C}$ ambient with an emissivity of 1.0. Solar insolation was applied on the package surfaces as per 10 CFR 71 [4]. Steady state analyses were performed.

The critical components in this package are foam, containment vessel wall, and vessel O-rings. Foam temperatures were the most critical and are compared in the results section below.

Since the package design must withstand 30-minutes HAC fire, a simulation was run to calculate the temperatures at the end of 30minutes for the critical components. Since the heat pipe operation is unidirectional, water vapor properties instead of heat pipe properties were used for this transient case. The initial conditions were the steady state temperatures without the solar insolation. These results are also discussed in the results section

\section{RESULTS}

Figure 11 shows the foam temperature $\left({ }^{\circ} \mathrm{F}\right)$ contours for the 20 watts thermal loading. The maximum temperature is $105^{\circ} \mathrm{C}\left(221^{\circ} \mathrm{F}\right)$ as compared to $151.7^{\circ} \mathrm{C}\left(305^{\circ} \mathrm{F}\right)$ for the proposed 9977 design. The axial heat transfer is so efficient that even a solid copper pipe in place of heat pipe will be quite effective and bring down the temperature to $112.8^{\circ} \mathrm{C}\left(253^{\circ} \mathrm{F}\right)$. A comparison of maximum temperatures for the important components is given in Table 2. 
Table 2 - Maximum Temperatures Comparison $\left({ }^{\circ} \mathrm{C} /{ }^{\circ} \mathrm{F}\right)$

\begin{tabular}{|l|c|c|c|}
\hline \multicolumn{1}{|c|}{ Loading } & CV Wall & CV O-Rings & Foam \\
\hline NCT Current Design & $250 / 482$ & $154 / 310$ & $152 / 305$ \\
\hline $\begin{array}{l}\text { NCT Heat Pipe } \\
\text { (20 watts) }\end{array}$ & $220 / 408$ & $104 / 220$ & $105 / 221$ \\
\hline $\begin{array}{l}\text { NCT Heat Pipe } \\
\text { (50 watts) }\end{array}$ & $353 / 668$ & $115 / 239$ & $116 / 240$ \\
\hline $\begin{array}{l}\text { NCT Copper } \\
\text { Cylinder (20 watts) }\end{array}$ & $359 / 679$ & $107 / 224$ & $123 / 254$ \\
\hline 30-Minutes Fire* & $160 / 320$ & $49 / 121$ & NA \\
\hline
\end{tabular}

* 30-Minutes fire results are calculated from initial conditions of NCT without solar heat flux.

\section{CONCLUSIONS}

Computer simulations show that a heat pipe system can be incorporated in the drum type package to reduce the component temperatures and increase the heat loading of the contents. However, much development work needs to be done before a heat pipe design can be implemented.

\section{PATH FORWARD}

It is planned to perform additional computer simulations and make design improvements that are practical. If the concept proves feasible, a proposal will be made for funding to procure heat pipes and test the concept. It is also important to develop analytical models of the heat pipe configuration and study its performance.

\section{ACKNOWLEDGMENT}

This paper was prepared in connection with work done under Contract No. DE-AC09-96SR18500 with the Department of Energy. By acceptance of this paper, the publisher and/or the recipient acknowledges the U.S. Government's rights to retain a nonexclusive, royalty-free license in and to any copyright covering this paper, along with the right to reproduce and to authorize others to reproduce all or part of the copyrighted paper.

\section{REFERENCES}

1. http://www.cheresources.com/htpipes.shtml.

2. Heat Transfer, by J.P. Holman, $5^{\text {th }}$ Edition, McGraw-Hill.

3. http://www.enertron-inc.com/enertron-products/heatpipes.php.

4. Packaging and Transportation of Radioactive Material, Code of Federal Regulations, Title 10, Part 71, Washington, DC (January 2006).

5. Hall, Michael L., Numerical Modeling of the Transient Thermohydrolic Behavior of High Temperature Heat Pipes for Space Reactor Applications, PhD Thesis, North Carolina State University, Raleigh, NC, March 1988.

6. http://THROHPUT.com.

7. MSC PATRAN/THERMAL, MSC Software Corp., Santa Anna, CA.

8. S-SARP-G-00001, Safety Analysis Report for Packaging Model 9977 Type B(M)F-96, Rev. 0, WSRC, (2006).

9. Power Heat Sinks, ThermaFlo Inc. http://www.thermaflo.com.
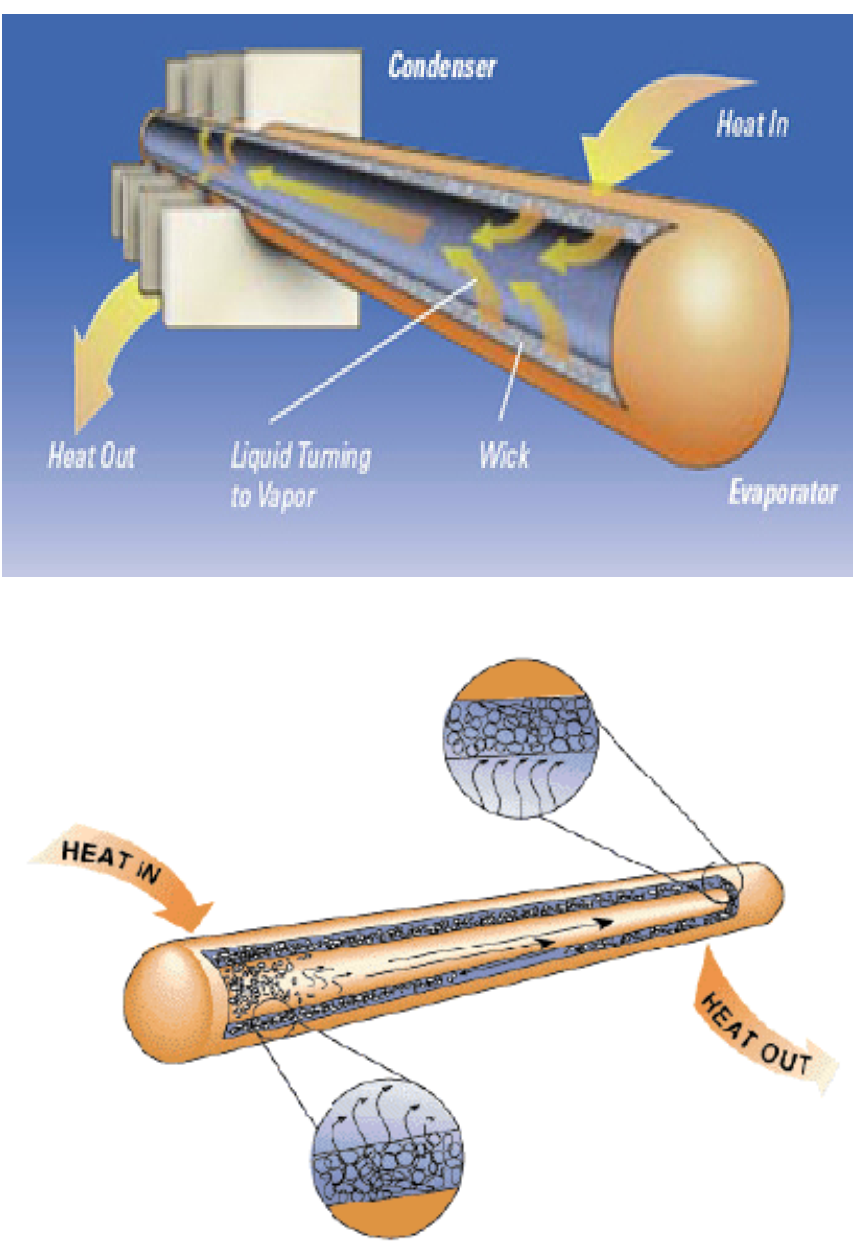

Figure 1 - Basic Heat Pipe

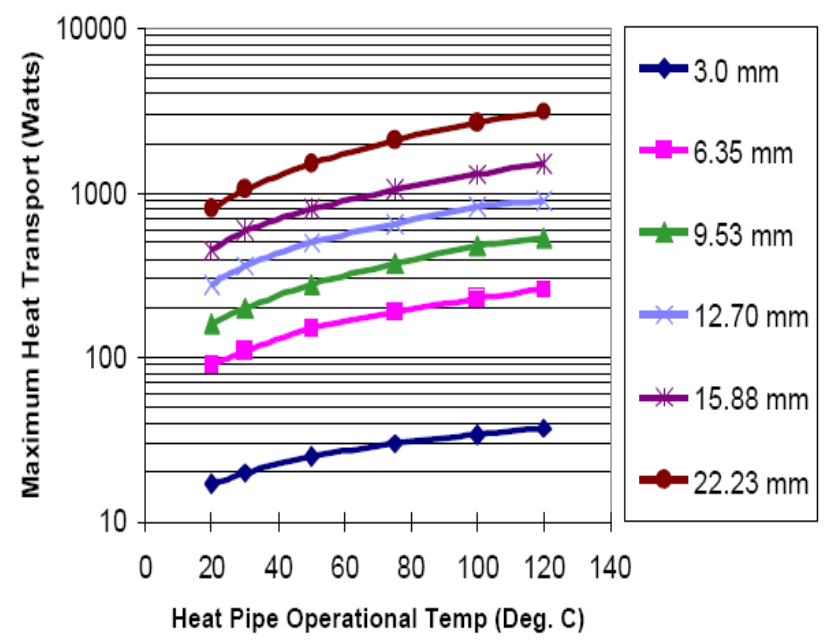

Figure 2 - Heat Pipe Performance 
Thermal Resistance vs. Heat Pipe Length

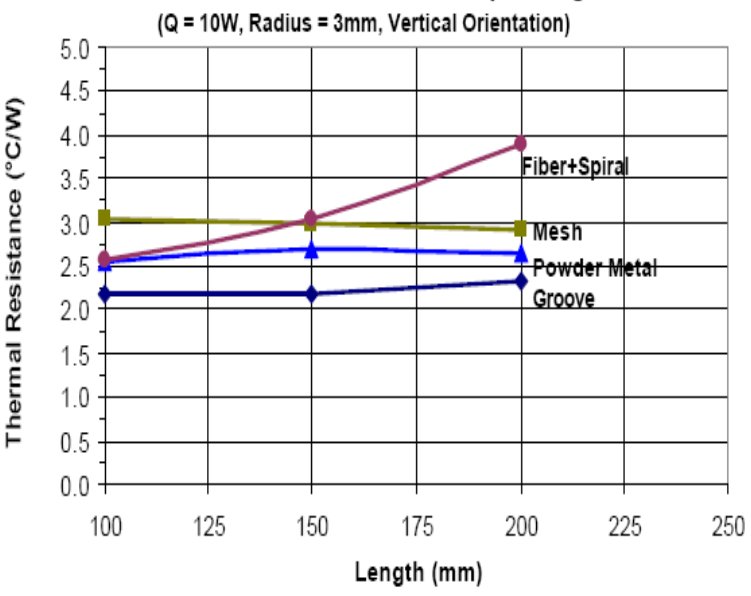

Figure 3 - Heat Pipe Performance

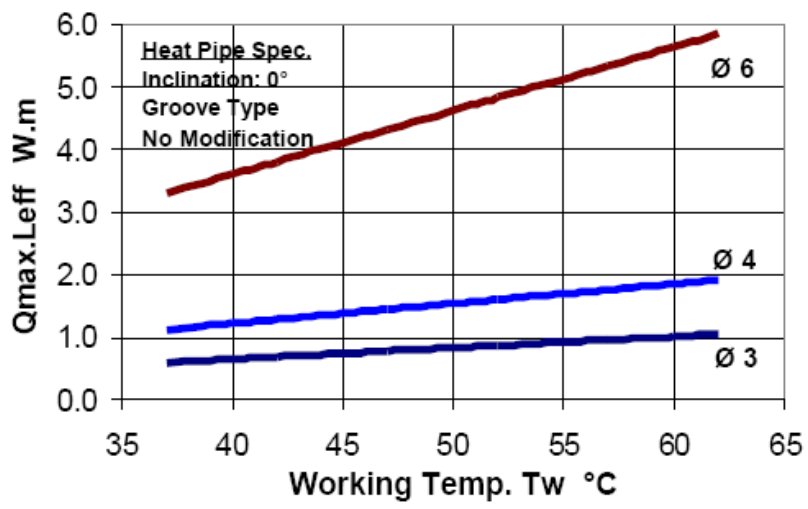

Figure 4 - The performance of various groove wick copper water heat pipes

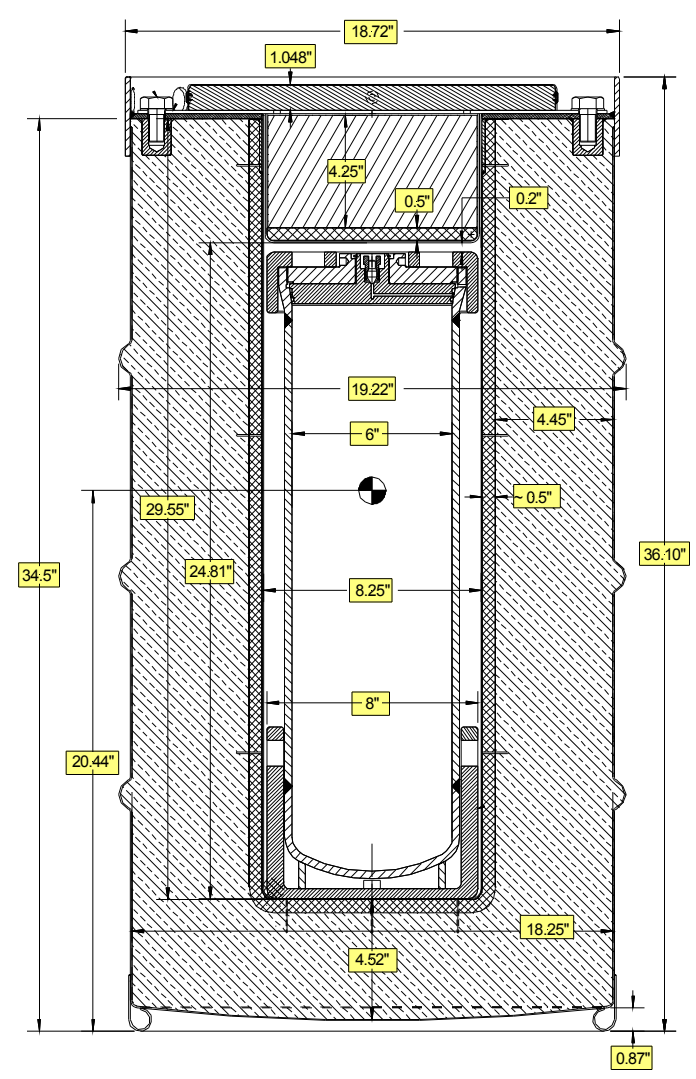

Figure 5 - 9977 Package Components

\section{Heat Pipe Conceptual Design}

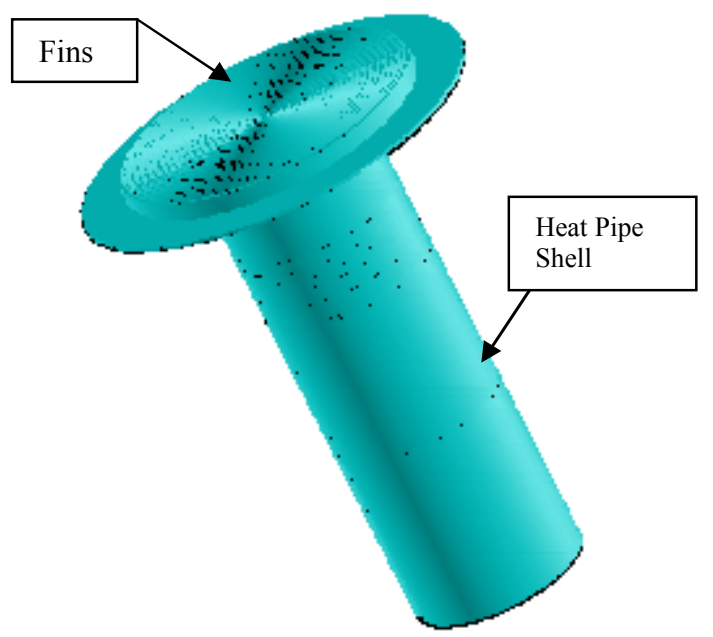

Figure 6 - Heat Pipe Rendering

\begin{tabular}{|c|c|c|c|c|c|}
\hline ? & Length & Width & Height & Weight & Surface Area \\
\hline & $3.000 \mathrm{in}$ & 12.252 in & $1.000 \mathrm{in}$ & $7.1 \mathrm{bs} / \mathrm{ft}$ & $79.6 \mathrm{in}^{2} / \mathrm{in}$ \\
\hline
\end{tabular}




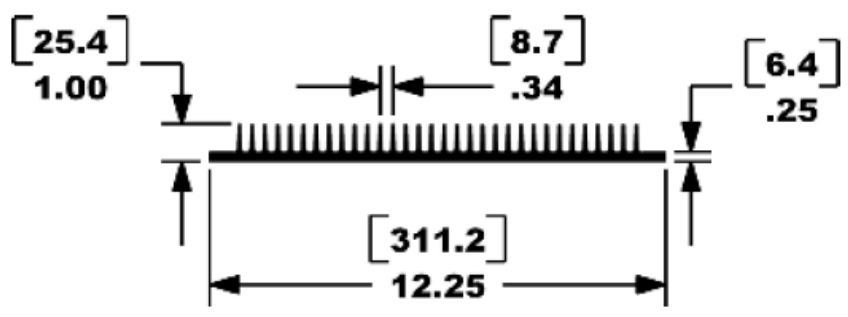

Figure 7 - Heat Sink E3113 from ThermaFlo

Natural Convection Performance Heat Sink Temperature Rise Over Ambient

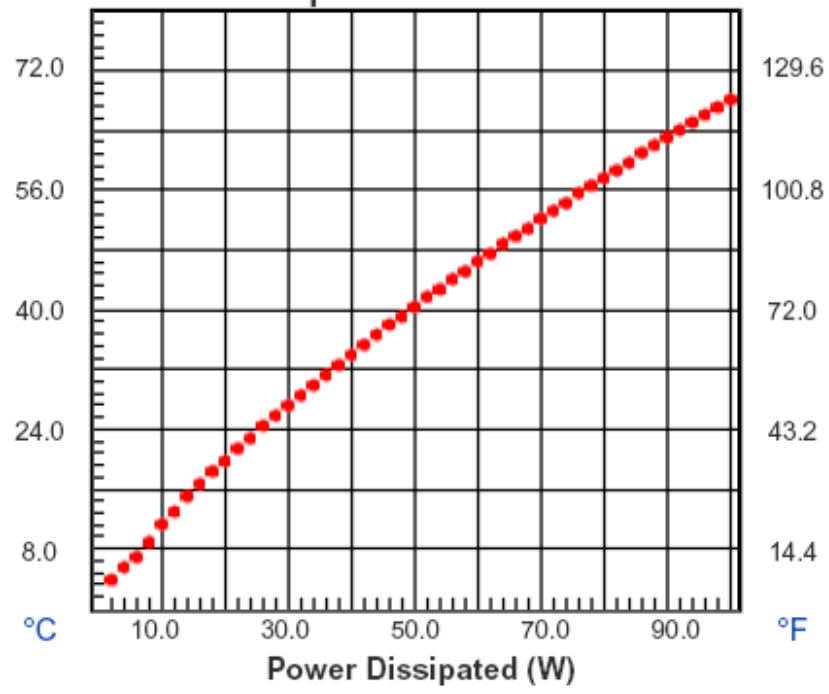

Figure 8 - Heat Sink Characteristics

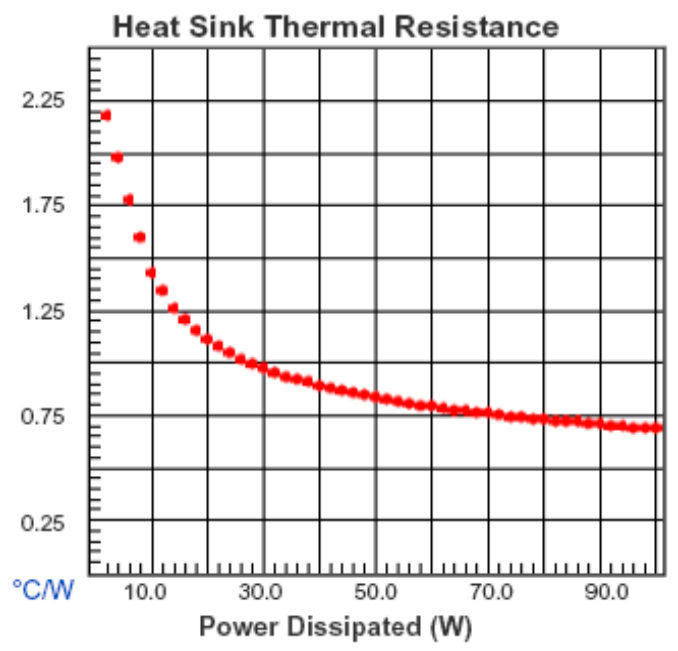

Figure 9 - Heat Sink Thermal resistance

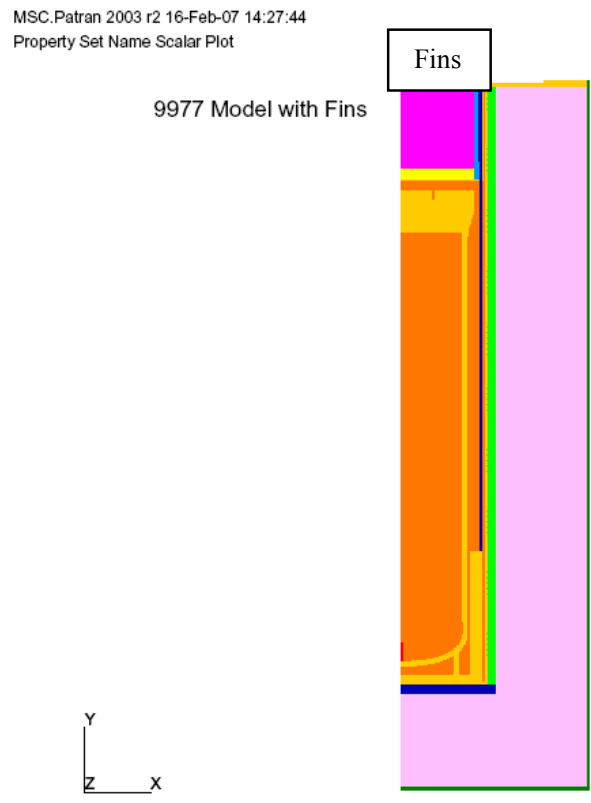

Figure 10 - 9977 Materials Model (Heat pipe is in Blue)

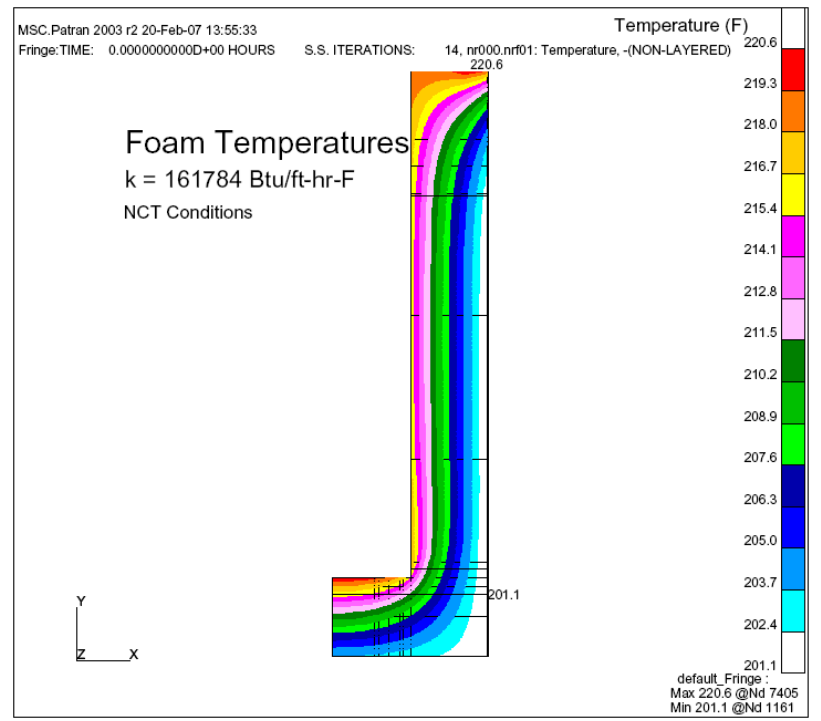

Figure 11 - Foam temperatures for 20 watts 